\title{
Tuning the Release Rate of Acidic Degradation Products through Macromolecular Design of Caprolactone-Based Copolymers
}

\author{
Minna Hakkarainen, Anders Höglund, Karin Odelius and Ann-Christine Albertsson* \\ Department of Fibre and Polymer Technology, School of Chemical Science and Engineering, \\ Royal Institute of Technology (KTH), S-100 44 Stockholm, Sweden \\ E-mail:aila@polymer.kth.se
}

\section{Experimental}

Materials. $\varepsilon$-caprolactone (CL) (Aldrich, Germany) was dried and distilled over calcium hydride $\left(\mathrm{CaH}_{2}\right)$ at reduced pressure prior to use. Stannous octoate $\left(\mathrm{SnOct}_{2}\right)$ (Aldrich, Germany) was distilled under reduced pressure. 1,5-dioxepan-2-one (DXO) was synthesized through a Bayer-Villiger oxidation according to the literature. ${ }^{1}$ The DXO was then purified by recrystallization from dry ether and two subsequent distillations under reduced pressure. The monomer was dried over $\mathrm{CaH}_{2}$ for $24 \mathrm{~h}$ prior to the final distillation. 2,2'-bis-( $\varepsilon$-caprolactone4-yl) propane (BCP) was synthesized according to a procedure given elsewhere and was recrystallized from acetone and dried under vacuum before used. ${ }^{2}$ All monomers were stored in a glovebox (Mbraun MB150B-G-I, Germany) under an inert atmosphere before use. Chloroform (BergmanLabora) stabilized with 2-methyl-2-butene, was dried over $\mathrm{CaH}_{2}$ for at least $24 \mathrm{~h}$ and distilled under reduced pressure in an inert atmosphere just before use. The cyclic tin alkoxide 1,1,6,6-tetra-n-butyl-1,6-distanna-2,5,7,10-tetraoxacyclodecane was synthesized from dibutyltin oxide and 1,2-ethanediol as described in the literature. ${ }^{3}$

Polymerization Technique. All reaction vessels were silanized and all glassware and syringes were flame-dried before use. The synthesis of the CL homopolymer and CL/DXO copolymers (triblock and multiblock) was performed according to the literature. ${ }^{4,5}$ The first 
monomer, initiator and chloroform were added to the reaction vessel under an inert atmosphere and allowed to react completely by ring-expansion polymerization before the second monomer was added. For the homopolymer only CL was added and let to react until complete conversion. For the multiblock copolymers DXO was added as the first monomer and $\mathrm{CL}$ as the second and for the triblock copolymer the reaction order was reversed. The formed polymers were precipitated in a mixture of cold hexane and methanol (95:5). Triblock and multiblock copolymer films were prepared by dissolving the copolymers in chloroform and solution-casting them into thin films $(0.1 \mathrm{~mm})$ on glass plates. The solvent was evaporated, and the films were dried under reduced pressure for at least 1 week before analysis. The CL/DXO network was synthesized by ring-opening polymerization of DXO and CL using BCP as crosslinking agent in the presence of SnOct $_{2}$ as catalyst. ${ }^{2}$ The thickness of the crosslinked samples was approximately $0.5 \mathrm{~mm}$.

Hydrolysis. The different copolymers and PCL homopolymer were exposed to hydrolytic degradation in a saline buffer of $\mathrm{pH} 7.4$ at $37{ }^{\circ} \mathrm{C}$. The saline buffer was prepared by dissolving $45 \mathrm{~g} \mathrm{NaCl}, 53.65 \mathrm{~g} \mathrm{Na}_{2} \mathrm{HPO}_{4} \cdot 7 \mathrm{H}_{2} \mathrm{O}$ and $10.6 \mathrm{~g} \mathrm{NaH}_{2} \mathrm{PO}_{4}$ in $4800 \mathrm{ml}$ of deionized water. The solution was allowed to stand over night; where after the $\mathrm{pH}$ of the buffer solution was adjusted to 7.4 by addition of $1 \mathrm{M} \mathrm{NaOH}$ and diluted to $5000 \mathrm{ml}$ with deionized water. The polymers were hydrolyzed in $20 \mathrm{ml}$ glass vials. $10 \mathrm{mg}$ of polymer and $10 \mathrm{ml}$ of the saline solution was added into each sample vial together with $100 \mu \mathrm{l} 0.04 \mathrm{wt} \% \mathrm{NaN}_{3}$ solution in order to prevent microbial growth. Sample vials were sealed with septa, and placed in a thermostatically controlled incubator. Temperature was set to $37{ }^{\circ} \mathrm{C}$ and rotation to $60 \mathrm{rpm}$. Samples were withdrawn from the test environment after 1 day, 7, 28, 91, 182, and 364 days of degradation, washed with deionized water and thereafter dried to constant weight under 
vacuum for two weeks. Triplicate samples were withdrawn and analyzed after each aging time.

Nuclear Magnetic Resonance, NMR. The composition of the materials were checked by ${ }^{1} \mathrm{H}$ NMR by comparing the peak intensities of the comonomers $\left(\delta_{\mathrm{CL}}=2.30 \mathrm{ppm}\right.$ and $\delta_{\mathrm{DXO}}=$ $3.75 \mathrm{ppm})$. The sequence lengths of the copolymers were determined with ${ }^{13} \mathrm{C}$ NMR spectroscopy and calculated according to Eq. (1) and (2): ${ }^{6}$

$$
\begin{aligned}
& \bar{L}_{C}=\frac{I_{C C}}{I_{C D}}+1=\frac{I_{C C}}{I_{D C}}+1 \\
& \bar{L}_{D}=\frac{I_{D D}}{I_{D C}}+1=\frac{I_{D D}}{I_{C D}}+1
\end{aligned}
$$

${ }^{1} \mathrm{H}$ NMR and ${ }^{13} \mathrm{C}$ NMR were obtained using a Bruker Advance DPX-400 Nuclear Magnetic Resonance spectrometer operating at $400 \mathrm{MHz}$ and $100 \mathrm{MHz}$ respectively. The samples (10 $\mathrm{mg}$ for ${ }^{1} \mathrm{H}$ NMR and $100 \mathrm{mg}$ for ${ }^{13} \mathrm{C} \mathrm{NMR}$ ) were dissolved in $1 \mathrm{~mL}$ deutero-chloroform $\left(\mathrm{CDCl}_{3}\right)$ in a $5 \mathrm{~mm}$ diameter sample tube and non-deuterated chloroform was used as an internal standard $\left(\delta=7.26\right.$ ppm for ${ }^{1} \mathrm{H}$ NMR and $\delta=77.0$ ppm for ${ }^{13} \mathrm{C}$ NMR).

Size Exclusion Chromatography, SEC. SEC was used to monitor the molecular weights of the polymers after polymerization and after different hydrolysis times. N,Ndimethylformamide (Lab-Scan, Sweden) was used as the eluent at a flow rate of $1.0 \mathrm{~mL} / \mathrm{min}$. The injection volume was $50 \mu \mathrm{L}$. A Waters 717 Plus autosampler and a Waters model M6000A solvent pump equipped with a PL-EMD 960 light scattering evaporative detector, two PLgel 10-mm mixed B columns $(300 \times 7.5 \mathrm{~mm})$ from Polymer Laboratories, and one Ultrahydrogel linear column $(300 \times 7.8 \mathrm{~mm})$ from Waters, connected to an IBM-compatible computer, were used. Narrow molecular-weight polystyrene standards were used for calibration. Millennium software version 3.20 was used to process the data. 
Differential Scanning Calorimetry, DSC. The thermal properties of the materials were investigated using a DSC (Mettler Toledo DSC 820 module) under nitrogen atmosphere. 2-5 mg of the polymer was encapsulated in a $40-\mu \mathrm{L}$ aluminum cap without pin. Samples were heated under a nitrogen gas flow of $50 \mathrm{~mL} / \mathrm{min}$ from -65 to $80{ }^{\circ} \mathrm{C}$ at a rate of $10{ }^{\circ} \mathrm{C} / \mathrm{min}$. Thereafter the samples were cooled from 80 to $-65^{\circ} \mathrm{C}$ at a rate of $10{ }^{\circ} \mathrm{C} / \mathrm{min}$ before being heated again from -65 to $80{ }^{\circ} \mathrm{C}$ at a rate of $10{ }^{\circ} \mathrm{C} / \mathrm{min}$. The melting temperatures, $\mathrm{T}_{\mathrm{m}}$, were noted as the maximum values of the melting peaks. The approximate crystallinity of the copolymers was calculated according to Eq. (3):

$$
w_{c}=\frac{\Delta H_{f}}{\Delta H_{f}{ }^{0}} \times 100
$$

where $w_{c}$ is the crystallinity, $\Delta H_{f}$ is the heat of fusion of the sample, and $\Delta H_{f}^{0}$ is the heat of fusion of $100 \%$ crystalline polymer, in this case $100 \%$ crystalline poly( $\varepsilon$-caprolactone). When evaluating the crystallinity, it was assumed that the only contribution to the heat of fusion comes from CL-blocks as poly(DXO) has earlier been shown to be a fully amorphous polymer having a $\mathrm{T}_{\mathrm{g}}$ between -35 and $-40{ }^{\circ} \mathrm{C} .^{7}$

Solid-phase extraction (SPE) of the hydrolysis products. After 1, 7, 28, 91,182 and 364 days samples were taken out and hydrolysis products were extracted from the phosphate buffer by solid phase extraction (SPE). At each time period three vials per material were taken out and extracted. SPE column material was ENV+ (Sorbent, Sweden). The column was first activated with $2 \mathrm{ml}$ methanol and then equilibrated with $2 \mathrm{ml}$ of clean phosphate buffer. Before application to the SPE column the $\mathrm{pH}$ of the phosphate buffer was adjusted to $\mathrm{pH} 2$ by addition of $37 \% \mathrm{HCl} .2 \mathrm{ml}$ of phosphate buffer with hydrolysis products was removed from each sample vial. $200 \mu \mathrm{l}$ of internal standard solution (2-hydroxyhexanoic acid $1 \mathrm{mg} / \mathrm{ml}$ 
water) was added and the $\mathrm{pH}$ was lowered to $\leq 2$ by adding $37 \% \mathrm{HCl}$. The phosphate buffer with the hydrolysis products was then allowed to penetrate the column. The analytes that were retarded into the column were eluted with $0.5 \mathrm{ml}$ acetonitrile and analyzed with GC-MS.

Gas Chromatography-Mass Spectrometry, GC-MS. Chromatographic separation and mass spectrometric detection was performed using a ThermoFinnigan (San José, CA, USA) GCQ GC-MS system. A Gerstel (Mülheim and der Ruhr, Germany) MPS2 autosampler was used to inject the samples. The GC was equipped with a WCOT CP-Wax $52 \mathrm{CB}$ column (30 $\mathrm{m} \times 0.25 \mathrm{~mm} \times 0.25 \mu \mathrm{m}$ ) from Varian (Lake Forest, CA, USA). The GC was programmed to start at $40{ }^{\circ} \mathrm{C}$, hold the temperature for $1 \mathrm{~min}$ and then increase the temperature by $10{ }^{\circ} \mathrm{C} / \mathrm{min}$ to $250{ }^{\circ} \mathrm{C}$. This temperature was held for $13 \mathrm{~min}$. Helium of $99.9999 \%$ purity from AGA (Stockholm, Sweden) was used as carrier gas at a constant average linear velocity of $40 \mathrm{~cm} / \mathrm{s}$ maintained by the Electronic Pressure Control (EPC) of the GC. The temperature of the injector was $250{ }^{\circ} \mathrm{C}$. A splitless injection mode was used. The temperatures of the transfer line and ion source were $275{ }^{\circ} \mathrm{C}$ and $180{ }^{\circ} \mathrm{C}$, respectively. The mass spectrometer was scanned in the range of $35-400 \mathrm{~m} / \mathrm{z}$ with a scan time of 0.43 seconds. Data was evaluated using the Xcalibur 1.2 software. The peak areas were calculated by integrating the Total Ion Current (TIC).

Water absorption and mass loss. The amount of water absorbed by the different polymers was measured after different hydrolysis times. At each time point three samples were withdrawn, washed with distilled water and the wet weight was determined. The percentage water absorption was determined by comparing the wet weight $\left(m_{w}\right)$ and dry weight $\left(m_{d}\right)$ after hydrolysis.

$$
\Delta m_{w}=\frac{m_{w}-m_{d}}{m_{d}} \times 100
$$


The percentage mass loss was determined by comparing the dry weight $\left(m_{d}\right)$ after hydrolysis with the initial weight $\left(m_{0}\right)$. The samples were dried for two weeks under vacuum $\left(0.5 \times 10^{-3}\right.$ mbar $)$ before the dry weight was determined.

$$
\Delta m_{d}=\frac{m_{0}-m_{d}}{m_{0}} \times 100
$$

\section{References}

(1) Mathisen, T.; Albertsson, A. C. Macromolecules 1989, 22, 3838-3842.

(2) Andronova, N.; Srivastava, R. K.; Albertsson, A.-C. Polymer 2005, 46, 6746-6755.

(3) Stridsberg, K.; Albertsson, A.-C. J. Polym. Sci., Part A: Polym. Chem. 1999, 37, $3407-3417$.

(4) Stridsberg, K.; Albertsson, A.-C. J. Polym. Sci., Part A: Polym. Chem. 2000, 38, 1774-1784.

(5) Andronova, N.; Finne, A.; Albertsson, A.-C. J. Polym. Sci., Part A: Polym. Chem. 2003, 41, 2412-2423.

(6) Kricheldorf, H. R.; Jonte, J. M.; Berl, M. Makromol. Chem. 1985, 12, 25-38.

(7) Mathisen, T.; Masus, K.; Albertsson, A. C. Macromolecules 1989, 22, 3842-3846. 